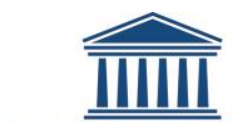 \\ UNIVERSITEIT \\ GENT
}

biblio.ugent.be

The UGent Institutional Repository is the electronic archiving and dissemination platform for all UGent research publications. Ghent University has implemented a mandate stipulating that all academic publications of UGent researchers should be deposited and archived in this repository. Except for items where current copyright restrictions apply, these papers are available in Open Access.

This item is the archived peer-reviewed author-version of:

The regulation of television sports broadcasting: a comparative analysis

Smith, P.; Evens, T. \& losifidis, P.

De Montfort University (UK), iMinds-MICT-Ghent University (Belgium), City University (UK) Media, Culture \& Society, 37(5), 720-736, 2015

To refer to or to cite this work, please use the citation to the published version:

Smith, P.; Evens, T. \& losifidis, P. (2015). The regulation of television sports broadcasting: a comparative analysis. Media, Culture \& Society, 37(5), 720-736. DOI:

$10.1177 / 0163443715577244$ 


\title{
The Regulation of Television Sports Broadcasting: A Comparative Analysis
}

\author{
Paul Smith, Tom Evens \& Petros Iosifidis
}

\section{Introduction}

The development of top-level professional sport into a highly valuable global industry has been well documented (e.g. Boyle and Haynes, 2000; Horne, 2006). Equally, it has also long been appreciated that sport is a sociocultural activity valued by millions of people across the globe (Coalter, 2007; Maguire, 1999). In both of these realms - the economic and the sociocultural - the media, and particularly television, has played a vital role in shaping the nature of contemporary sport. On the one hand, sports organisations and television broadcasters have built a synergetic relationship that has allowed both to further their commercial interests. In this sense, the commodification of sport has served the interests of all the main participants within the 'sports-media-business complex', including media conglomerates, marketing agencies, brands and sponsors, sports event organisers, sports associations and even professional athletes, if not always sports fans (Andrews, 2003; Law et al, 2002; Nicholson, 2007). Just as significantly, on the other hand, in many countries free-toair television coverage of sports events and competitions, by either public service broadcasters and/or national commercial networks, has facilitated shared viewing experiences, which have fostered a sense of national identity and cultural citizenship (Rowe, 2004; Scherer and Whitson, 2009). More generally, free-to air broadcasting of sporting events has played a key role in the establishment of sport as a significant part of popular culture. Paradoxically, free-to-air sports broadcasting provided the foundations on which the highly commercialised sports industry of today is built.

This article focuses on how the contrasting perspectives on television and sport cited above have been reflected in different approaches to the regulation of sports broadcasting. First, competition policy aims to facilitate free, fair and effective competition within the sports broadcasting market (Iosifidis, 2011). And, second, sector specific media regulation, in this case, major events legislation (also commonly referred to as listed events or anti-siphoning legislation), aims to guarantee the public's right to information and preserve free access to 
television coverage of major national or international sporting events, such as the Olympic Games, or the FIFA World Cup (Lefever, 2012). However, there have been repeated calls from pay-TV broadcasters and some sports organisations to limit the application of both of these strands of regulation, particularly the latter (Scherer and Sam, 2012). Here, we make the case for a regulatory approach that seeks to balance the commercial priorities of broadcasters and sports organisations with the wider sociocultural benefits citizens gain from free-to-air sports broadcasting. Based on the comparative analysis of a range of different national sports broadcasting markets, this article suggests that in many cases the balance between commerce and culture in sports broadcasting has shifted too far in favour of the commercial interests of dominant pay-TV broadcasters and sports organisations seeking to maximise their income from the sale of broadcast rights. As a result, citizens often face either the loss of access to television coverage of key sporting events and competitions and/or rising bills from pay-TV services. Against this background, we contend that policy makers and regulators should: first, resist pressure from pay-TV broadcasters and/or sporting organisations to abolish/undermine major events legislation, or consider the introduction of such legislation if it is not already in place; and, second, tackle the market power of sports channel owners and/or broadcast delivery platforms through the application of competition law, albeit with consideration for the cultural specificities of sports broadcasting.

Ultimately, decisions on the regulation of sports broadcasting are political ones about the balance between the free market and government intervention in the economy and the type of society we want to live in. With this in mind, the article begins by providing a brief overview of the politics of sports broadcasting regulation, with particular reference to major events legislation and competition law. The main part of the article then provides an analysis of the regulation of sports broadcasting across a range of different countries, namely Australia, Brazil, India, Italy, South Africa, the United Kingdom (UK) and the United States (US), as well as the European Union (EU). ${ }^{1}$ Admittedly, at least in part, these examples have been selected because they reflect the interests of the authors, but they also offer a relatively global outlook and serve to illustrate three general regulatory approaches: i) free market; ii) strong regulation; and, iii) balanced regulation. Most significantly, this comparative analysis provides evidence to suggest that a balanced (or at least close to balanced) approach to sports broadcasting regulation, which best serves the combined interests of broadcasters, sports organisations and citizens, can be achieved in practice. 


\section{The Politics of Sports Broadcasting Regulation}

The introduction of major events legislation in some of the countries discussed below (as well as the EU) has been justified on the grounds that, in the absence of such legislation, coverage of high profile sporting events will tend to migrate from free-to-air broadcasting to pay-TV. There is certainly considerable evidence to support this point of view. Perhaps most notably, in Europe, since the 1990s, live television coverage of top level domestic football has largely shifted from free-to-air to pay-TV. In the US, the migration of sports coverage to pay-TV has been less apparent (Szymanski, 2006), but, in recent years, even in the US, there has been a discernible shift in the availability of premium sports programming from free-to-air broadcasters to (cable and/or satellite) pay-TV broadcasters (Zimbalist, 2006). For example, in 2006, the US pay-TV broadcaster, ESPN, prompted considerable controversy when it acquired the rights to broadcast the traditional Monday Night Football game, which had been available to free-to-air viewers via US network television for over thirty years. At the same time, however, it should be emphasised that much, if not most, of the sports coverage provided by pay-TV broadcasters does not consist of programming previously available via free-to-air broadcasters. Pay-TV broadcasters have hugely increased the total amount of sports programming available on television. For example, in the UK, Boyle and Haynes (2000: ix) note how 2,800 hours of television sport was produced by four free-to-air broadcasters in 1989, whereas, by 2012, BSkyB alone was providing around 35,000 hours of sports programming per year across four separate sports channels (excluding Sky Sports News) for its UK subscribers (Oxford Economics, 2012: 19). For the most part, the additional sports programming provided by pay-TV broadcasters over the last couple of decades has consisted of either more extensive coverage of sports that were previously shown by free-toair broadcasters, or coverage of sports and sporting events that previously received little, if any, airtime on free-to-air television. BskyB, for instance, was recently estimated to dedicate nearly half of its annual total of 35,000 hours of sport to 'non-core' sports, including, yachting, angling, darts, netball, speedway and badminton (ibid.).

The growth of pay-TV has provided significant benefits for both viewers and sports organisations, but this does not lessen the case for major events legislation. The argument for major events legislation is based on its potential to promote (and/or preserve) cultural citizenship in two key ways. First, major events legislation may be justified on grounds of equity. For example, the Australian government's recent review of its anti-siphoning scheme stressed that it had received 'many submissions from the general public' that expressed 
concern about the 'costs of pay television' (DBCDE, 2010: 11). In countries like Brazil, India and South Africa, which exhibit even wider disparities between social classes, the exclusion of low income groups from access to sporting events broadcast exclusively on pay-TV is likely to be even more significant. Secondly, one of the main benefits of ensuring that major sporting events are broadcast on free-to-air television is the generation of what economists refer to as 'positive network externalities'. In simple terms, an individual not only enjoys the event and the 'conversational network' though viewing, their participation also adds value to the network for everyone (Boardman and Hargreaves-Heap, 1999). This concept is highly significant to the debate on major events legislation because it can be seen to apply to the difficult to quantify, but no less real, shared benefits that can result from the coverage of major sporting events on universally available free-to-air broadcasting.

For the most part, opposition to major events legislation stems from an underlying commitment to free market principles. The opposition of many sports organisations to the listing of their sports is based on the belief that they are best placed to judge how to further the interests of their own sport, and in particular how to balance the potentially increased revenue to be gained via pay-TV with the benefits (not least commercial via increased sponsorship revenue) of greater exposure through free-to-air broadcasting. However, the key argument in support of major events legislation is not that policy makers and regulators know better than individual sports organisations how to promote the best interests of a particular sport. Rather, it is, as discussed above, that the wider public interest in the form of cultural citizenship is served by the availability of particular sporting events on free-to-air television. For sports organisations whose events are protected for free-to-air coverage, the existence of major events legislation may be a source of frustration, but it is not particularly unusual in democratic societies for certain property rights to be subject to state regulation in the public interest. For example, planning laws mean that those who live in heritage properties cannot do with them exactly what they want. To promote cultural citizenship, the same is true for sports organisations and listed events. An extra sentence needed to make this comparison clearer.

The other main advocates of a free market in sports broadcasting have been pay-TV broadcasters, who frequently claim that too many events are covered by major events legislation. According to pay-TV broadcasters (and others??), this is, at least in part, a product of the lack of clear criteria against which to judge whether an event should be listed 
(Solberg, 2002). The EU is able to counter such criticism by reference to its four 'reliable indicators of the importance of events for society', but the same line of defence is not available beyond Europe (see below).

To date, the application of competition law to sports broadcasting has focused mainly on the collective selling by sports leagues of the rights to broadcast exclusive live coverage of their sports. The case for regulatory intervention is based on the argument that by selling their rights collectively through a league teams act as a cartel. From this perspective, collective selling agreements have a tendency to restrict competition in three main ways. First, collective selling gives the league market power to dictate the price of broadcast rights, which leads to inflated prices for both broadcasters (upstream) and consumers (downstream). Second, collective selling arrangements also tend to limit the availability of rights to sports events. This is because teams often fear that live broadcast coverage of matches will undermine their attendance revenue. By selling their broadcast rights collectively, teams have a mechanism through which they can limit the total number (and time) of games broadcast so as to lessen the impact on attendance revenue. Third, collective selling arrangements can strengthen the market position of the most important broadcasters because they are the only operators who are able to bid for all the rights in a package. In theory, if broadcast rights were sold by individual clubs, rather than collectively, there would be more possibilities for other broadcasters to obtain rights, which, in turn, would foster competition in broadcasting.

In defence of the collective selling of broadcast rights, it is pointed out that sport, and in particular team sport, has a number of distinct economic characteristics which make the application of general competition law inappropriate. First, the production of sporting contests in professional team sports requires joint production by at least two individual teams. Consequently, unlike the underhand and/or secret behaviour that typifies cartels in other areas of business, team sports, by definition, need to co-operate and do so openly through leagues and tournaments. Second, a league or competition is more exiting and attractive to fans (and broadcasters) if the outcome is uncertain. Consequently, no team has a long term interest in the failure of its main sporting competitor(s). Supporters of collective selling claim that, if individual teams are allowed to sell the broadcast rights to their matches, it leads to significant income disparities between teams, which reduces the competitive balance of the league and, in turn, undermines the long term popularity of the competition. There is considerable evidence to support this argument from leagues where individual selling has 
been allowed (see the case of Italy below). By contrast, leagues that operate collective selling share the revenue from broadcast rights much more evenly, albeit in various ways and to varying degrees. On this basis, it can be argued that the collective selling of broadcast rights may be pro-competitive, rather than anti-competitive, and as such should be granted exemption from competition law.

The competition issues raised by broadcasters seeking to use sports programming to ensure a competitive advantage over their rivals are just as, if not more significant, than those related to collective selling by sports leagues. Thoughout the world, the ownership of exclusive live premium sports rights has become a key source of market power within contemporary broadcasting. One way to address this issue might be to simply impose a ban on exclusive deals for live sports rights (Harbord and Szymanski, 2004). However, such a move could well fatally undermine the sports programming market. Broadcasters are unlikely to be willing to invest significant sums to provide coverage of sporting events also available elsewhere. The alternative approach adopted by competition law, particularly within Europe, at both national and EU level, has been to treat the broadcast rights for exclusive live sports programming, particularly football, in accordance with the 'essential facilities doctrine' (Levey, 1999). The 'essential facilities doctrine' effectively denotes that certain upstream (i.e. sports rights) inputs are essential/indispensable for downstream broadcasters to compete in the relevant market (i.e. sports programming) and cannot easily be replicated without significantly raising costs. Following on from this, to facilitate competition, access is provided to the 'essential facility' for all market players on 'fair, reasonable and non-discriminatory' terms, which are overseen by broadcasting and/or competition regulators.

The 'essential facilities' approach is most salient in relation to disputes between sports channel owners and controllers/owners of delivery platforms. For sports channels owned by sports teams (as well other independent owners) access to the most popular delivery platforms (e.g. cable network, DTH satellite etc.) is a prerequisite for commercial success. Equally, in pay-TV markets where the main broadcast sports rights are also owned by the owner of a delivery platform, the owners of rival distribution platforms will require access to sports programming/channels in order to be competitive. Broadly speaking, competition issues related to the distribution of sports programming have predominately arisen in US broadcasting as a result of the former scenario (Zimbalist, 2006), whereas in pay-TV markets in Europe and beyond the latter issue has often prompted more concern from competition 
authorities and broadcasting regulators (Smith, 2013). Regulators should be prepared (and have political support) to intervene so as to guarantee reasonable terms of access for both sports channels and delivery platforms, but this is not always the case.

\section{Comparing the Regulation of Sports Broadcasting}

Of course, the regulation of sports broadcasting in each of the countries considered here reflects the particular historical, political and cultural traditions of the country concerned. For the purpose of comparative analysis, however, the type and degree of regulatory intervention can usefully be seen as a continuum with the 'free market' at one end and 'strong regulation' at the other. In the 'free market' case, sports broadcasting is completely left to the market with no (or minimal) role for public service broadcasting and only a 'light touch' regulatory framework, which does little to tackle the market power of dominant commercial interests or to ensure free-to-air television coverage of major sports events. In the 'strong regulation' case, public service (or commercial free-to-air) broadcaster(s) are granted a dominant role in sports broadcasting, supported by a regulatory approach that guarantees free-to-air television coverage for an extensive list of major (and not so major) sporting events. In addition, competition policy principles are applied with little regard for the distinctive economic and sociocultural features of sporting competitions and sports broadcasting.

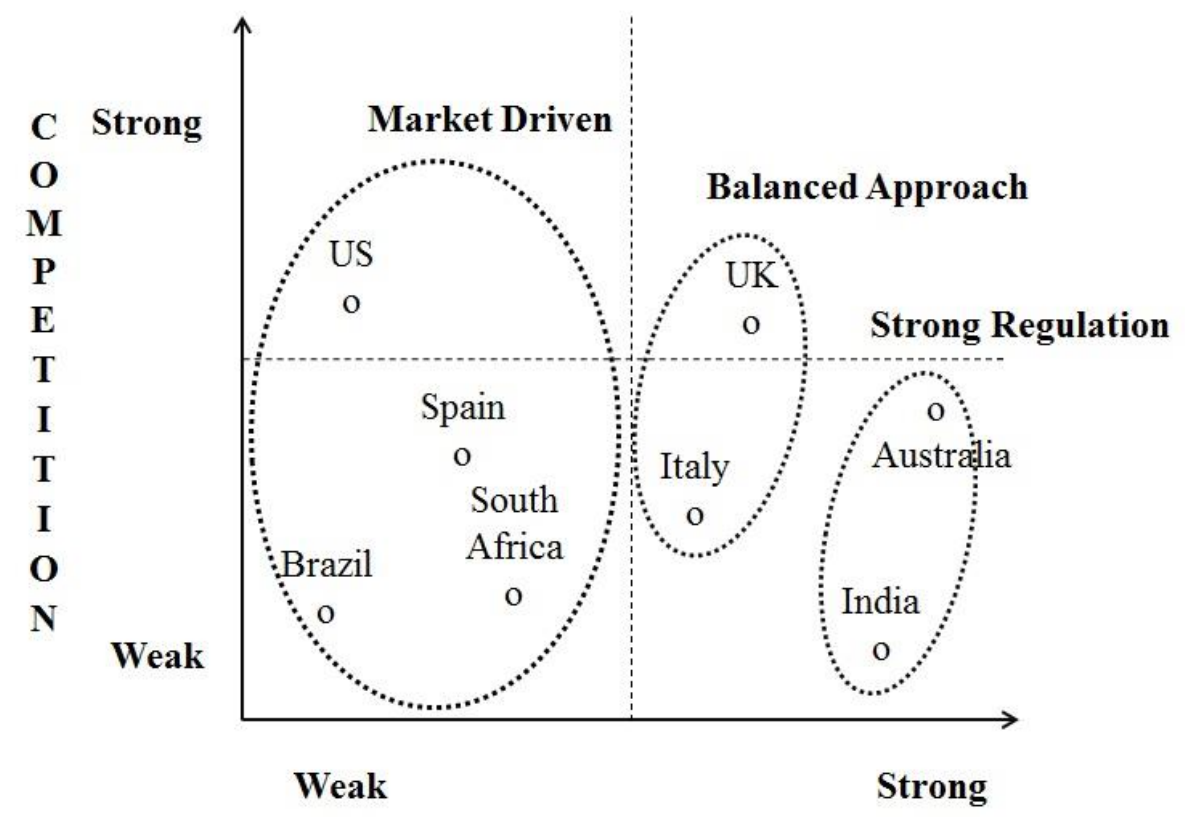

LISTED EVENTS

Figure 1: Free market versus strong regulation 
In reality, most countries fall somewhere between these two extremes and some (e.g. India) combine an interventionist approach to major events legislation with a less interventionist approach to the application of competition law (or vice versa). Figure 1 provides a general indication of the different regulatory positions adopted in relation to sports broadcasting in each of the countries analysed. On this basis, we suggest that three different regulatory approaches are clearly discernible within global sports broadcasting: a free market model; a strong regulation model; and, a balanced model. The first two approaches tend to produce significant imbalances between the cultural and commercial interests associated with sports broadcasting, whereas the latter approach is defined by clear attempts to balance these potentially conflicting interests.

\section{The Free Market Approach}

Broadly speaking, sports broadcasting in Brazil, the US and South Africa can be characterised as predominantly market-driven. In each of these countries, there is no (or only, in the case of South Africa, fairly weak) major events legislation. The application of competition law has been virtually non-existent in Brazil and South Africa, but has been more significant in the US. Perhaps most notably, the free market approach has been a defining feature of US broadcasting since its very inception. In terms of the development of US sports broadcasting, three key points are worth noting, the first two of which have led to its 'free market' categorisation. First, the public service broadcaster, PBS, was quickly overpowered by commercial networks in the bidding process for popular sports rights (Walker and Ferguson, 1998). Second, during the 1970s, rules introduced by the US broadcasting regulator, the Federal Communications Commission (FCC), designed to prevent cable broadcasters from acquiring the rights to broadcast 'specific events' (e.g. the baseball World Series final, the Super Bowl of American football and the Olympic Games) were successfully challenged in court on the grounds that they infringed the First Amendment's right to freedom of speech (Wolohan, 2009). However, despite these two developments, (commercial) free-to-air broadcasters continue to play a leading role in US sports broadcasting. Third, the 1961 Sports Broadcasting Act was explicitly designed by Congress to ensure that US competition law would take into consideration the special features of sports broadcasting and thus permit the collective (i.e. cartel) selling of broadcast rights by the major US sporting leagues. Rather than general competition law, the prevention of anticompetitive behaviour in US sports broadcasting has largely been left to the FCC, which has tended to focus on disputes over the distribution of sports channels between channel owners 
and pay-TV delivery platforms on a case by case basis, especially with regard to regional sports networks (Moss, 2008). For example, in 2007, a high profile exclusive distribution deal between the MLB Network (baseball) and the satellite provider, DirecTV, prevented access to the channel(s) by cable broadcasters. After the FCC threatened regulatory intervention, the MLB lessened its exclusive reliance on DirecTV and allowed access to alternative distributors (Associated Press, 2007). However, the general trend toward the migration of live coverage of major sports to league-owned premium channels could well result in the need for a more comprehensive policy intervention in the US to ensure a competitive sports broadcasting market.

As in the US, Brazil's approach to broadcasting policy has been largely driven by commercial, rather than sociocultural objectives (Sinclair, 1999). However, unlike the US, Brazil has a relatively weak tradition of competition law. The last decade or so has witnessed the establishment of a new competition law framework in Brazil, but, to date, this has had little impact on the established media companies and, most significantly, has not prevented the leading commercial broadcaster, TV Globo, from retaining its dominant position in Brazilian broadcasting, as well as Brazilian media more generally (Fox and Waisbord, 2002). However, Brazil's main competition authority, the Administrative Council for Economic Defence (CADE), has acted to end TV Globo's exclusive control of some top domestic and international soccer rights, forcing Globo to sublicense its popular SporTV channels to rival pay-TV operators (OECD, 2010). Just as, if not more significantly, there is also no major events legislation in Brazil. To date, this has not resulted in a migration of live sports coverage to pay-TV channels, largely because of the high costs associated with subscription services. However, fuelled by the country's recent rapid economic growth, a prosperous middle class is emerging in Brazil and pay-TV has experienced extraordinary growth during the last few years, which, according to television analysts, is set to continue. In 2013, Brazil had around 17 million pay-TV households, by 2017, this figure is predicted to rise to around 40 million (Forester, 2013). As a result, a form of major events legislation may soon be required in Brazil to guarantee large numbers of Brazilian citizens, especially the less welloff and those in rural areas, access to live free-to-air television coverage of major sporting events.

Over the last couple of decades, South Africa has also adopted a market driven approach to (sports) broadcasting (Duncan and Glen, 2010). The defining feature of the South African 
sports broadcasting market is the dominant position of the pay-TV broadcaster, MultiChoice, and in particular its digital service, DStv, which includes the SuperSport channel(s). MultiChoice has built its commercial success on the extensive (and often exclusive) television coverage of South Africa's most popular sports: rugby, football and cricket. In response, during the early 2000s, the government introduced major events legislation, which has enabled the country's main public service broadcaster, the South African Broadcasting Corporation (SABC), to claw back coverage of some major sporting events. Furthermore, live coverage of matches during the 2010 FIFA World Cup Finals (hosted by South Africa) was provided by the commercial free-to-air broadcaster, e.tv. However, the protection offered to free-to-air viewers by South Africa's major events legislation has some significant limitations. First, a pay-TV broadcaster is not prevented from acquiring the rights to a national sporting event, but is merely required to sublicense the rights to such an event to a free-to-air broadcaster. And second, South Africa's sports broadcasting regulations do not require the live coverage of national sporting events, only that such events 'be broadcast live, delayed live or delayed by a free-to-air broadcasting service' (ICASA, 2010a). In practice therefore South Africa's major events legislation has meant that the television rights to most events are first acquired by MultiChoice. To fulfil its public service mandate and offer some coverage of the event, the (cash strapped) SABC is then forced to negotiate with the subscription broadcaster for secondary rights. Just as importantly, to date at least, competition law has had even less impact on the South African sports broadcasting market. MultiChoice's rivals have all urged South Africa's communications regulator, the ICASA, to intervene and tackle competition concerns related the distribution of sports channels (ICASA, 2010b). For South Africa to benefit from a more competitive broadcasting market, the ICASA will need to respond.

\section{The Strong Regulation Approach}

Australia and (to a lesser extent) India can be seen as examples of the strong regulation of sports broadcasting. This is mainly due to the form of major events legislation adopted in each country. The Australian system has two key features, which distinguish it from the EU's approach (see below). First, it is based on a 'first choice' approach, which gives free-to-air broadcasters priority in the acquisition of broadcast rights and prevents pay-TV broadcasters from obtaining the exclusive rights to listed events. Second, the range and the number of sporting events covered by the Australian list are much more extensive than those adopted in Europe. For instance, the Australian list (2006-2010) was estimated to cover over 1800 
events in a given year (excluding four-yearly tournaments such as the Olympics), whereas most European countries cover fewer than 100 events (excluding four-yearly tournaments) (DBCDE, 2010). Taken together, these features have led to competition for sports rights in Australia to be skewed significantly in favour of (commercial) free-to-air broadcasters. At least partly as a result, the Australian scheme has also not always promoted the cultural citizenship of Australian viewers in the way originally intended. In some cases, free-to-air broadcasters have profited by reselling sports rights to pay-TV operators. On other occasions, free-to-air broadcasters have been accused of 'hoarding' rights with no intention to broadcast merely so as to prevent pay-TV operators from obtaining valuable rights (Perrine, 2001). Legislative changes have subsequently been introduced to tackle such abuses, but it could still be argued that the long list of events protected for broadcast on free-to-air television has produced a relatively underdeveloped (in terms of economic value) sports broadcasting market in Australia. However, this may be set to change. Towards the end of 2013, the newly elected conservative Liberal-National coalition government announced its plan for 'deregulation in the communications portfolio' (DoC, 2013). In response, the Australian Subscription Television and Radio Association (ASTRA) has already put forward a plan to permit sports organisations to sell the rights for listed events 'in parallel' to both free-to-air broadcasters and pay-TV (Heffernan, 2014). Any move in this direction would certainly highlight the need for a more interventionist approach to the application of competition law to sports broadcasting in Australia. To date, competition law has not prevented the establishment of a highly concentrated Australian pay-TV sector, dominated by Foxtel (jointly owned by News Corporation and Telstra) and its only sports channels, Fox Sports. In fact, the most significant competition case to focus on sports broadcasting, the so-called C7 case, served only to confirm Foxtel's dominance of the Australian pay-TV market (Healey, 2009).

India's major events legislation can also be seen to provide strong regulatory protection for the coverage of major sporting events on free-to-air television, via the Indian public service television broadcaster, Doordarshan. The (2007) Sports Broadcasting Signal (mandatory sharing with Prasar Bharati) Act prevents any pay-TV broadcaster from carrying live coverage of 'sporting events of national importance', unless it simultaneously shares its signal with Doordarshan. However, the law offers little guidance on the criteria used to select 'sporting events of national importance'. This is perhaps most problematic in relation to broadcast coverage of India's national cricket team. Cricket is by far India's most popular 
sport and yet key decisions over which international cricket Test matches are to be safeguarded for free-to-air broadcast coverage are left to the discretion of the Indian government. Consequently, to the consternation and confusion of many observers, some Test matches involving the Indian cricket team are made available via Doordarshan, but others are not, perhaps most notably the final Test match of India's cricketing hero, Sachin Tendulkar (India v. West Indies, November 2013). Just as problematically, India's major events legislation also specifies that the sharing of television rights for listed events should take place on the basis of a revenue sharing agreement between the parties, with advertising revenue shared between the content rights owner/holder and Doordarshan in the ratio of not less than 75:25. However, this system has often resulted in Doordarshan effectively losing money when broadcasting listed events, as it could have earned more advertising revenue with its regular programming than the 25 per cent share of advertising revenue it gains from broadcasting a listed event.

Unlike major events legislation, competition law has had little impact on sports broadcasting in India. However, given the importance of cricket to Indian pay-TV (akin to football in Europe), it is perhaps unsurprising that the attention of the recently (2009) established Competition Commission of India (CCI) has been drawn to the selling of television cricket rights. Since the 1990s, the awarding of cricket rights has repeatedly been mired in controversy, often related to the conduct of the Board of Control for Cricket in India (BCCI), the national governing body of all cricket in India. In 2013, the CCI ruled that the BCCI had abused its dominant position in the award of commercial contracts to the highly lucrative Indian Premier League (IPL) and fined the governing body six per cent of average annual revenue over the last three years, around Rs 52.24 crore (CCI, 2013). In all likelihood, further regulatory intervention will be required to ensure a more open, transparent and competitive market for the selling of cricket rights. Currently, the most valuable sports rights are divided between a number of major broadcasters - News Corporation (Star Sports), Sony (SonySix) and Zee TV (Ten Sports). However, with the growth of satellite and digital cable television, the commercial incentives to expand and dominate the Indian market are likely to intensify. In these circumstances, the CCI will have a crucial role to play to ensure that Indian viewers are able to benefit from a competitive sports broadcasting market. 


\section{The Balanced Regulation Approach}

The EU's regulation of sports broadcasting provides the best example of a balanced approach. Initially adopted during the late 1990s as part of the renewed Television Without Frontiers Directive and then subsequently incorporated into the 2007 (and then 2010) Audiovisual Media Services Directive (EC, 2010, Article 14), EU major events legislation is based on a 'dual rights' system. This approach (unlike in Australia) allows the television rights to listed events to be purchased by either free-to-air or pay-TV broadcasters, but not broadcast exclusively on pay-TV, unless there is no interest in providing coverage of an event from a free-to-air broadcaster. However, the implementation of the EU's major events legislation has not been without its problems. First, in accordance with the terms of the Directive, whilst a number of Member States, including some of the largest, have taken up the opportunity to submit lists of major events to the Commission, most (20 out of 28) have opted not to do so. Second, the EU's major events legislation contains a number of 'vague definitions' (Evens and Lefever, 2011). For example, the Directive states that a major event should not be broadcast in such a way that a 'substantial proportion' of the public are deprived of the possibility of following the event on free television. However, it does not provide a precise definition of 'substantial proportion'. As a result, Member States have been left to offer their own slightly different definitions of the term, ranging from 70 to 95 per cent of the population. And, third, the Directive itself also provides little guidance on what might reasonably be regarded as an 'event of major importance for society'. However, the Commission has moved to remedy this point. To be formally agreed by the Commission, events included in a proposed list from a Member State are required to meet at least two of the following criteria deemed to be 'reliable indicators of the importance of events for society':

i) a special general resonance within the Member State, and not simply a significance to those who ordinarily follow the sport or activity concerned;

ii) a generally recognised, distinct cultural importance for the population in the Member State, in particular as a catalyst of cultural identity;

iii) involvement of the national team in the event concerned in the context of a competition or tournament of international importance; and

iv) the fact that the event has traditionally been broadcast on free-to-air television and has commanded large audiences. (EC, 2007a). 
Crucially, the relatively clear set of criteria adopted by the Commission for the selection of listed events has provided EU major events legislation with a degree of protection from legal challenge. Most notably, in 2007, FIFA and UEFA challenged the lists of major events adopted by Belgium and the UK on the grounds that, unlike in other Member States, both countries had listed entire FIFA (World Cup) and UEFA (European Championship) tournaments, rather than just the matches involving their respective countries and/or semifinal and final matches. In reaching its judgement, the European Court made explicit reference to the listing criteria employed by the Commission and declared that it was legitimate for some Members States to include the whole tournament in their national list, even if this was not the case in other Member States (European Court, 2011). Given this example, the adoption of clear criteria for the selection of events to be protected for free-toair coverage in other countries, such as Australia and India, may be seen as a means to provide increased legitimacy for major events legislation, rather than a means to facilitate the removal of events from a list as often sought by pay-TV broadcasters and/or some sports organisations.

The EU's application of competition law to sports broadcasting has followed a similarly balanced approach. Instead of condemning the collective selling of football rights outright, the Commission has sought to amend the practice so as to dilute its anti-competitive tendencies. For example, during the early 2000s, the Commission negotiated a number of important changes to the way that UEFA sold the rights to its Champions League football competition, including the introduction of a three-year limit to the length of any exclusive deal, the division of television rights into a number of separate (gold and silver) packages and the unbundling of new media rights. According to the Commission, UEFA's modified arrangements were sufficient to allow UEFA to continue to sell its rights collectively 'to the benefit of all stakeholders in the game' (EC, 2003). The UEFA case proved particularly significant because it provided a template for the Commission's approach to other instances of the collective selling of football rights by national leagues, most notably the Bundesliga in Germany and the Premier League (PL) in England. In the Bundesliga case, again, the duration of any exclusive deal was limited to three years and the rights were unbundled into nine different packages, including separate packages for television and new media rights (EC, 2005a). The PL case proved more challenging, but, following lengthy negotiations between the Commission and the PL, it was agreed the rights for live PL matches (seasons 2006-7 to 2009-10) would be sold in 'six balanced packages with no one bidder being able to buy all 
six packages' (EC, 2005b). This move effectively ended BSkyB's monopoly of the live rights to PL football. More generally, the EU's approach to the application of competition law means that collective selling remains the dominant model for the selling of broadcast rights to top level football in Europe. Indeed, the European Commission has praised collective selling as 'a tool for achieving greater solidarity within sports' (EC, 2007b).

The UK has also adopted a relatively balanced approach to the regulation of sports broadcasting. In reaction to BSkyB's sports rights buying strategy, reforms to strengthen UK major events legislation were introduced as part of the 1996 Broadcasting Act (Smith, 2010). Subsequently, the events included on the list and the level of protection offered for free-to-air broadcasters has been the subject of much public and political debate. Most notably, in 1998, the UK's list was divided between (Group A) events, which should be broadcast live on freeto-air television, and (Group B) events, which may be broadcast exclusively live on pay-TV, as long as adequate provision has been made for 'secondary' (i.e.. highlights) coverage on free-to-air television. The relegation of England's cricket Test matches to the B list remains controversial, but, overall, the UK's approach to major events legislation may be seen as a reasonable attempt to balance the need to ensure certain national events are available to all with the commercial interests of pay-TV broadcasters and sporting organisations. The UK's approach to the application of competition law has also been relatively balanced. On the one hand, the UK has shown an appreciation of the special economic and cultural features of sports broadcasting, most notably when, during the late-1990s, the Restrictive Practices Court ruled that the collective selling of PL football rights was 'not unreasonable and not against the public interest' (RPC, 1999). On the other hand, the UK's main communications regulator, Ofcom, has attempted to tackle BSkyB's market power in the UK pay-TV market through the introduction of a 'wholesale must offer' system and regulated pricing (Ofcom, 2010). However, to date, this intervention has only prompted a lengthy legal struggle with BSkyB at the UK's Competitions Appeal Tribunal (Sweney, 2014).

In recent years at least, Italy could also be argued to have adopted a fairly balanced approach to the regulation of sports broadcasting. First, in 2011, Italy extended the scope of its major events legislation to offer protection to a number of national sporting events not included in the country's initial (1999) submission to the EU, including the Italian MotoGP Grand Prix and Six Nations rugby matches involving the Italian national team. Second, even more significantly, Italy has also recently moved from an individual to a collective system for the 
selling of television rights to its top football leagues, Serie A and Serie B. Traditionally Italian clubs had sold the rights to their matches on an individual basis (as it is the case in Spain), and this was a position that was also legally sanctioned in 1999 (Law 78/1999). However, amidst the unprecedented financial and sporting scandal that engulfed Italian football at the end of the 2005-2006 football season, the government introduced legislation (Law 106/ 2007), which aimed to reduce the income disparities between Italian clubs and improve competitive balance by introducing the joint ownership of broadcasting rights between the League and the participating clubs, as well as sanctioning the 'centralised commercialisation' of such rights. Less positively, Sky Italia, owned by News Corporation, and formed following a (2003) merger between Stream (News Corporation) and Telepiu (Vivendi), has established a dominant position in the Italian pay-TV market. This has occurred despite the inclusion of certain regulatory conditions following the merger, such as limits to the duration of exclusive rights to premium content (including football rights) to two years. With this in mind, it could be argued that, as in the UK, there remains a need for the more rigorous application of competition law to the distribution of sports channels in order to achieve a properly balanced approach to sports broadcasting regulation.

\section{Conclusion}

Based on a comparative analysis of television sports broadcasting regulation across a range of different countries, as well as the EU, this article has highlighted the value (and achievability) of a regulatory approach that seeks to balance the commercial interests of broadcasters and sports organisations with the wider socio-cultural interests of citizens and society as a whole. More specifically, a number of key points are worth highlighting. First, there is little, if any, evidence to support the notion put forward by some opponents of major events legislation that such legislation is no longer required in a digital media environment characterised by new ways for viewers to watch (and pay) for sports programming. On the contrary, in such a media environment, where direct payment for popular programming is likely to become increasingly common, it can be argued that there is more, not less, need for regulatory intervention to enhance cultural citizenship via free-to-air coverage of major sports events. On this basis, there is a case for the introduction of major events legislation in countries, such as Brazil and the US, and the strengthening of such legislation in countries, such as South Africa. Second, the EU's approach to major events legislation demonstrates the value of a relatively clear set of criteria for the inclusion of events on any list to be protected for free-toair broadcasting. A similar approach could be adopted in countries where the existing criteria 
are unclear, such as India and Australia, which, particularly in the case of Australia, may lead to a marginal reduction in the number of events covered, but would enhance the legitimacy of the legislation.

Third, to date, the application of competition law to sports broadcasting has focused mostly on the sports rights market (i.e. the selling of television rights by sporting organisations to broadcasters). The examples considered here suggest that the case for the collective selling of broadcast rights by sports leagues has been widely accepted. However, as again best demonstrated by the EU, regulatory safeguards may be required, such as the unbundling of rights into a number of different packages, to limit the anti-competitive tendencies associated with collective selling. Other countries, perhaps most notably India, could benefit from the adoption of a similar approach.

Fourth, the attention of policy makers and regulators should now turn to ensuring increased competition within the sports programming market (i.e. the 'downstream' market for the distribution of sports channels/programming to consumers). To a greater or lesser degree, in almost all of the countries considered here the sports programming market was characterised by the market power of dominant pay-TV broadcasters (i.e. BSkyB, Foxtel, MultiChoice, Sky Italia and TV Globo). To some extent, the market power of pay-TV broadcasters has been/can be diluted through the unbundled sale of rights packages, but this approach does not automatically further consumer interests. For example, the unbundling approach does not rule out the possibility of one party acquiring the most significant rights packages and dominating the sports programming market. To ensure competition in the pay-TV market, regulatory intervention is required in the form of a wholesale obligation to supply sports channels to rival delivery platforms (as, at least partially, applied in the UK). Commercial rivals might agree channel distribution deals without the need for regulatory intervention, but in the absence of regulatory intervention, any such deals are overly reliant on the commercial incentives and/or goodwill of dominant pay-TV broadcasters. Ultimately, the reward for regulatory intervention along these lines could prove to be lower retail prices for consumers. 


\section{References}

Andrews, D.L. (2003). Sport and the transnationalizing media corporation. Journal of Media Economics, 16(4), 235-251.

Associated Press (2007) 'FCC Investigating MLB's Proposed DirecTV Deal', ESPN MLB: 22 February. Available at: < http://sports.espn.go.com/mlb/news/story?id=2775761> (Accessed March 2013).

Author (2013)??

Boardman, A.E. and Hargreaves-Heap, S.P. (1999) 'Network externalities and government restrictions on satellite broadcasting of key sporting events', Journal of Cultural Economics, 23(3), 167-181.

Boyle, R. and R. Haynes (2000). Power Play: Sport, the Media and Popular Culture. London: Longman.

CCI (Competition Commission of India) (2013) Case No. 61/2010: 8 February. Available at: <http://www.cci.gov.in/May2011/OrderOfCommission/612010.pdf> Accessed April 2014.

Coalter, F. (2007). A Wider Social Role for Sport: Who's keeping the Score? London: Routledge.

DBCDE (Department for Broadband, Communications and the Digital Economy) (2010). Sport on Television: A Review of the Anti-Siphoning Scheme in the Contemporary Digital Environment: Review Report. Available at: <http://www.dbcde.gov.au/_data/assets/pdf_file/0017/131462/Review_Report__Sport_on_Television-the_antisiphoning_scheme_in_the_contemporary_digital_environment_-_25-11-2010.pdf> (Accessed August 2012).

DoC (Department of Communications) (2013) Deregulation Framing Paper. Available at: < http://www.communications.gov.au/_data/assets/pdf_file/0010/204877/FramingPaper.pdf > (Accessed April 2014).

Duncan, J. and Glenn, I. (2010). Turning Points in South African Television Policy and Practice, in Moyo, D. And Chuma, W. (eds.) Media Policy in a Changing Southern Africa: Critical Reflections on Media Reforms in the Global Age (pp. 39-72). Pretoria: UNISA Press.

EC (European Commission) (2003). Commission clears UEFA's new policy regarding the sale of media rights to the Champions League. Press Release, 24 July.

EC (European Commission) (2005a). Commission Decision of 19 January 2005 relating to a proceeding pursuant to Article 81 of the EC Treaty and Article 53(1) of the EEA 
agreement (Case COMP/C.2/37.214 - Joint Selling of the Media Rights to the German Bundesliga).

EC (European Commission) (2005b). Commission Receives Improved Commitments from FAPL Over Sale of Media Rights. Press Release, 17 November.

EC (European Commission (2007a). Commission Decision of 16 October 2007 on the capability with EU law of measures to be taken by the United Kingdom Pursuant to Article $3 a$ (1) of Council Directive 89/552/EEC on the coordination of certain provisions laid down by law, regulation or administrative action in Member States concerning the provision of television broadcast activities. Available at <http://eurlex.europa.eu/LexUriServ/site/en/oj/2007/1_295/1_29520071114en00120027.pdf> (Accessed August 2012).

EC (European Commission) (2007b). White Paper on Sport. Brussels: European Commission. EC (European Commission) (2010). Directive 2010/13/EU of the European Parliament and of the Council of 10 March 2010 on the coordination of certain provisions laid down by law, regulation or administrative action in Member States concerning the provision of audiovisual media services (Audiovisual Media Services Directive). Available at: $<$ http://eurlex.europa.eu/LexUriServ/LexUriServ.do?uri=OJ:L:2010:095:0001:0024:EN:PDF> (Accessed August 2012).

European Court (2011). Judgements in Cases T-385/07, T-55/08 and T-68/08, Press Release, 17 February. Available at: <http://curia.europa.eu/jcms/upload/docs/application/pdf/201102/cp110009en.pdf> Accessed September 2012.

Evens, T. and Lefever, K. (2011). Watching the Football Game: Broadcasting Rights for the European Digital Television Market. Journal of Sport \& Social Issues, 35(1), 33-49.

Evens, T. and Lefever, K. (2013). The struggle for platform leadership in the European sports broadcasting market, in B. Hutchins and D. Rowe (Eds.), Digital Media Sport: Technology, Power and Identity in the Network Society (pp. 66-80). New York: Routledge. Forester, C. (2013) 'Brazil Pay-TV Could be 40m by 2017', Advanced Television: 8 August. Available at: <http://advanced-television.com/2013/08/08/brazil-pay-tv-could-be-40m-by2017/> Accessed April 2014.

Fox, E. and Waisbord, S. (2002). Latin American media: a long view of politics and markets, in R. Mansell, R. Samarajiva and A. Mahan (eds.) Networking knowledge for information societies. Institutions \& intervention (pp. 303-310). Delft: Delft University Press. 
Harbord, D. and Szymanski, S. (2004) 'Football Trials', European Competition Law Review, 25 (2): 117-22.

Healey, D. (2009). Australia, in I. Blackshaw, S. Cornelius and R. Siekmann (eds.) TV rights and sport: legal aspects (pp. 215-234). The Hague: T.M.C. Asser Press.

Heffernan, M. (2014) 'Pay TV Pushes for Anti-Siphoning Changes for Sport', Sydney Morning Herald: 31 March. Available at: < http://www.smh.com.au/business/media-andmarketing/pay-tv-pushes-for-antisiphoning-changes-for-sport-20140331-35u32.html> Accessed April 2014.

Horne, J. (2006). Sport in consumer culture. New York: Palgrave Macmillan.

ICASA (Independent Communications Authority of South Africa) (2010a). Sport Broadcasting Services Regulations, 2010. Available at <https://www.icasa.org.za/LegislationRegulations/ExistingRegulations/SportsBroadcasting Rights/FinalRegulations/tabid/403/ctl/ItemDetails/mid/1310/ItemID/281/Default.aspx> (Accessed January 2013).

ICASA (Independent Communications Authority of South Africa) (2010b) Findings and Reasonings Document on the Sport Broadcasting Services Regulations. Available at $<$ https://www.icasa.org.za/LegislationRegulations/FinalRegulations/BroadcastingRegulatio ns/SportsBroadcastingRights/tabid/245/ctl/ItemDetails/mid/1310/ItemID/280/Default.aspx $>$ (Accessed April 2014).

Iosifidis, P. (2011). Global Media and Communication Policy. Basingstoke: Palgrave Macmillan.

Law, A., Harvey, J. and Kemp, S. (2002). The global sports mass media oligopoly: the three usual suspects and more. International Review for the Sociology of Sport, 37(3/4), 279302.

Lefever, K. (2012). New Media and Sport: International Legal Aspects. The Hague: T.M.C. Asser Press.

Maguire, J. (1999). Global Sport: Identities, Societies, Civilizations. Cambridge: Polity Press.

Matos, C. (2011). Media and Democracy in Brazil. Westminster Papers in Communication and Culture, 8(1), 178-196.

Moss, D. (2008). Regional sports networks, competition, and the consumer. Loyola Consumer Law Review, 21(1), 56-74.

Nicholson, M. (2007). Sport and the Media: Managing the Nexus. Oxford: Elsevier. 
OECD (2010). Competition law and policy in Brazil. A peer review. Paris: OECD Publications.

Perrine, J.B. (2001). Constitutional challenges to anti-siphoning laws in the United States and Australia. Sports Administration, 3(1), 22-31.

Oxford Economics (2012) The Economic Impact of Sky on the UK: A Report Prepared for Sky. Available at: < http://corporate.sky.com/documents/pdf/publications/2012/the_economic_impact_of_sky_ on_the_uk > Accessed March 2014.

Rowe, D. (2004). Fulfilling the cultural mission: popular genre and public remit. European Journal of Cultural Studies, 7(3), 381-400.

RPC (1999) Hon. Mr. Justice Ferris: Restrictive Practices Court Judgement, London: Restrictive Practices Court.

Scherer, J. and Whitson, D. (2009). Public Broadcasting, Sport, and Cultural Citizenship: The Future of Sport on the Canadian Broadcasting Corporation? International Review for the Sociology of Sport, 44(2/3), 213-229.

Scherer, J. and Sam, M.P. (2012). Public Broadcasting, Sport and Cultural Citizenship: Sky's the Limit in New Zealand? Media Culture \& Society, 34(1), 101-111.

Sinclair, J. (1999). Latin America television: a global view. New York: Oxford University Press.

Solberg, H. A. (2002b) ‘Cultural Prescription: The European Commission's Listed Events Regulation - Over Reaction?, Culture, Sport \& Society, 5(2), 1-28.

Smith, P. (2010). The Politics of Sports Rights: The Regulation of Television Sports Rights in the UK, Convergence, 16(3), 316-333.

Smith, P. (2013). Too Much or Not Enough? Competition Law and Television Broadcasting Regulation in the United Kingdom. Westminster Papers in Communication and Culture, 9(3), 143-164.

Sweney, M. (2014) 'BT Wins Court Battle Forcing Review of Sky Wholesale Pricing Decision', The Guardian, 17 February. Available at: < http://www.theguardian.com/media/2014/feb/17/bt-sky-wholesale-pricing-bskyb-skysports> Accessed April 2104.

Szymanski, S. (2006b) 'Why have premium sports rights migrated to pay-tv in Europe but not in the US?', in C. Jeanrenaud and S. Késenne (eds.) The Economics of Sport and the Media. Northampton: Edward Elgar, pp. 148-159.

Walker, J. and Ferguson, D. (1998). The Broadcast Television Industry. New York: Allyn and Bacon. 
Wolohan, J.T. (2009). United States, in I. Blackshaw, S. Cornelius and R. Siekmann (eds.) TV rights and sport: legal aspects (pp. 567-586). The Hague: T.M.C. Asser Press.

Zimbalist, A. (2006) 'Economic Perspectives on Market Power in the Telecasting of US Team Sports' in Jeanrenaud, C. and Kesenne, S. (eds.) The Economics of Sport and the Media, Cheltenham: Edward Elgar: pp.160-78.

\footnotetext{
${ }^{1}$ A more detailed analysis of each of these countries is provided in Author (2013)??
} 